\title{
Impact of other-cell interferences on downlink capacity in WCDMA Network
}

\author{
Fadoua Thami Alami \\ Abdelmalek Essaadi University \\ Morocco
}

\author{
Noura Aknin \\ Abdelmalek Essaadi University \\ Morocco
}

\author{
Ahmed El Moussaoui \\ Abdelmalek Essaadi University \\ Morocco
}

\begin{abstract}
Before the establishment of the UMTS network, operators are obliged to make the planning process to ensure a better quality of service (QOS) for mobile stations belonging to WCDMA cells. This process consists of estimating a set of parameters characterizing the radio cell in the downlink direction. Among them, we are interested in the Node B total required power $\boldsymbol{P}_{T o t}$, and the maximum cell capacity, in the case of voice only and in the case of voice/video. To implement the effect of the other-cell interferences power, modeled as a fraction $f_{D L}$ of the own-cell received power, on various radio parameters described previously, we focused our study on two different scenarios: the first is based on an isolated cell and the second, on multiple cells. In addition, when the WCDMA cell reaches its maximum capacity, the introduction of admission control algorithms is essential to maintain the QOS of the ongoing mobile stations. For this purpose, we have proposed an admission control algorithm, based both on the Node $B$ total required power and the cell loading factor. This algorithm gives rigorous results compared to the existing ones in the literature.
\end{abstract}

Keywords-WCDMA; planning process; downlink; capacity estimation; other-cell interferences; ; wn-cell interferences; Node B total required power; admission control.

\section{INTRODUCTION}

The estimation of the WCDMA cell capacity is based on the signal to interferences ratio received at the level of an active mobile station in downlink and at the level of the Node B [1-2]. This ratio is expressed as a function of the required power of a mobile station $i$ activating a service $j$ and as a function of various problems harming the radio interface, such as: other-toown cell interferences and thermal noise [1-4]. Thus, WCDMA network must allocate power by taking into account the required quality of service characterizing each service, and environmental conditions. This power is dynamically adjusted several times to preserve the energy per bit to noise spectral density ratio $\left(E_{b} / N_{0}\right)$ constant $[1-8]$.

In this work, we are interested in assessing and estimating the maximum downlink cell capacity in the case of a single-service and multi-services network, for two different scenarios: an isolated cell case, and a multiple-cells network case. The objective of this study is to highlight the effect of other-to-own-cell interference on WCDMA downlink capacity. In addition, network operators, look for controlling the admission of new mobiles stations, to prevent overloading status and fight against the degradation of link quality of communications already established. In this sense, we used two admission control algorithms to propose another, more efficient and rigorous, which takes into account two parameters: the maximum cell loading factor and Node B total available power $P_{\max }$.

\section{NODE B TOTAL POWER ESTIMATION IN A MULTI- SERVICE NETWORK}

A. Link quality equation in a multiple cell and in an isolated cell cases

The estimation of the maximum cell capacity and Node B total required power is based on the link quality equation $E_{b} / N_{O}$ required for user $i$ activating a certain service $j$ (voice, video, web browsing, etc) in a cell $\mathrm{m}$. This equation takes into account various radio interface problems: multipath propagation, neighboring cell effect, path loss, thermal noise equipment etc...

The expression of $E_{b} / N_{0}$ equation for a user $i$ $\left(i=1 \ldots N_{u s e r(j)}^{(m)}\right)$ activating a service $j(j=1 \ldots k)$ in the cell $m$, in the case of a multiple cells case, can be written as:

$$
\left.E_{b} / N_{0}\right)_{i j}{ }^{(m)}=\frac{W p_{i j}{ }^{(m)} / L_{i j}{ }^{(m)}}{R_{i j}{ }^{(m)}\left(\left(1-\alpha_{i j}{ }^{(m)}\right)\left(P_{T o t}{ }^{(m)}-p_{i j}{ }^{(m)}\right) / L_{i j}{ }^{(m)}+P_{T o t}{ }^{(m)} \sum_{n=1, n \neq m}^{M} 1 / L_{i j m}{ }^{(n)}+P_{N}\right)}
$$

Where: $P_{\text {Tot }}:$ Total downlink transmission power in the cell $m ; M$ : Number of cells in the network; $P_{N}$ : Thermal noise power of the mobile; $R_{i j}{ }^{(m)}$ : The bit rate of a user $i$ activating a service $j$ in a cell $m ; W$ : The chip rate $; P_{i j}{ }^{(m)}$ : Transmission power required for a user $i$ activating a service $j$ in a cell $m$; $L_{i j}{ }^{(m)}$ : Pathloss between the Node B (of the cell $m$ ) and a user $i$ activating a service $j$ in the cell $m ; L_{i j m}{ }^{(n)}$ : Pathloss between a Node B (of the cell $n$ ) and a user $i$ activating a service $j$ in the cell $m ; \alpha_{i j}{ }^{(m)}$ : orthogonality factor of a user $i$ activating a service $j$ in the cell $m$. It depends on the multipath.

It is assumed that the total transmit power of different Node Bs is equal.

In the case of an isolated cell, the neighboring cells effect is absent. Then, the equation (1) should be modified as follows:

$$
\left.E_{b} / N_{0}\right)_{i j}{ }^{(m)}=\frac{W p_{i j}{ }^{(m)} / L_{i j}{ }^{(m)}}{R_{i j}{ }^{(m)}\left(\left(1-\alpha_{i j}{ }^{(m)}\right)\left(P_{T o t}{ }^{(m)}-p_{i j}{ }^{(m)}\right) / L_{i j}{ }^{(m)}+P_{N}\right)}
$$

\section{B. Node B total power expression}

From equation (1) the required power expression of a mobile station $\mathrm{i}$ activating a service $\mathrm{j}$ in a cell $\mathrm{m}$ is: 


$$
p_{i j}{ }^{(m)}=\frac{\left(1-\alpha_{i j}{ }^{(m)}+f_{D L i j}{ }^{(m)}\right) P_{T o t}{ }^{(m)}}{\frac{W}{\left.E_{b} / N_{0}\right)_{i j}{ }^{(m)} R_{i j}{ }^{(m)} v_{i j}{ }^{(m)}}+\left(1-\alpha_{i j}{ }^{(m)}\right)}+\frac{P_{N} L_{i j}{ }^{(m)}}{\frac{W}{\left.E_{b} / N_{0}\right)_{i j}{ }^{(m)} R_{i j}{ }^{(m)} v_{i j}{ }^{(m)}}+\left(1-\alpha_{i j}{ }^{(m)}\right)}
$$

Where:

$v_{i j}{ }^{(m)}$ is the activity factor, which is used to evaluate the average utilization of the radio resources for the various services (voice, video ....). And we have:

$$
f_{D L i j}{ }^{(m)}=\frac{I_{o t h e r}}{I_{\text {own }}}=\sum_{n=1, n \neq m}^{M} \frac{L_{i j}{ }^{(m)}}{L_{i j m}{ }^{(n)}}
$$

is defined as the other-to-own-cell interferences ratio received at a user $i$ activating a service $j$ in a cell $m$.

Where:

- $I_{\text {own }}$ : own-cell interferences, includes the total received power from the users connected to the cell.

- $I_{\text {other }}$ : other-cell interferences, includes the transmissions in the adjacent cells operating at the same frequency.

In downlink, this ratio $\left(0 \leq f_{D L} \leq 1\right)$ depends mainly on the user geographical position as well as on the neighboring Node Bs power. Thus it's different for each user. If the user is located on the cell edge, the $f_{D L}$ value is high. On the contrary, if the user is close to his serving cell, $f_{D L}$ value is small.

To simplify equation (3), we put:

$$
X_{i j}{ }^{(m)}=\frac{\left(1-\alpha_{i j}^{(m)}+f_{D L i j}{ }^{(m)}\right)}{\frac{W}{\left.E_{b} / N_{0}\right)_{i j}^{(m)} R_{i j}^{(m)} v_{i j}^{(m)}}+\left(1-\alpha_{i j}^{(m)}\right)}, Y_{i j}^{(m)}=\frac{L_{i j}^{(m)}}{\frac{W}{\left.E_{b} / N_{0}\right)_{i j}^{(m)} R_{i j}^{(m)} v_{i j}^{(m)}}+\left(1-\alpha_{i j}^{(m)}\right)}
$$

And we consider that:

$$
P_{\text {Tot }}=\sum_{j=1}^{k} \sum_{i=1}^{N_{\text {uer }(j)}^{(m)}} p_{i j}^{(m)}
$$

Consequently:

$$
P_{T o t}=\frac{P_{N} \sum_{j=1}^{k} \sum_{i=1}^{N_{u s e r(j)}^{(m)}} Y_{i j}{ }^{(m)}}{1-\sum_{j=1}^{k} \sum_{i=1}^{N_{\text {user }(j)}^{(m)}} X_{i j}{ }^{(m)}}
$$

Equation (3) can be rearranged as:

$$
p_{i j}{ }^{(m)}=\left(X_{i j}{ }^{(m)}+Y_{i j}{ }^{(m)} \frac{1-\sum_{j=1}^{k} \sum_{i=1}^{N_{u s e r(j)}{ }^{(m)}} X_{i j}{ }^{(m)}}{\sum_{j=1}^{k} \sum_{i=1}^{N_{u s e r(j)}{ }^{(m)}} Y_{i j}{ }^{(m)}}\right) P_{T o t}
$$

From equation (8), we conclude that the power consumed by the mobile station is a fraction of the Node B total available power, where:

$$
k_{i j}{ }^{(m)}=X_{i j}{ }^{(m)}+Y_{i j}{ }^{(m)} \frac{1-\sum_{j=1}^{k} \sum_{i=1}^{N_{u s e r(j)}{ }^{(m)}} X_{i j}{ }^{(m)}}{\sum_{j=1}^{k} \sum_{i=1}^{N_{u s e r(j)}{ }^{(m)}} Y_{i j}{ }^{(m)}}
$$

Is the amount of radio resources to be allocated to mobile station. Therefore, and by considering the user in an average position, the Node B total required power in a multi-service network becomes:

$$
\begin{aligned}
& P_{N} L_{(\text {moy })} \sum_{j=1}^{k} \sum_{i=1}^{N_{\text {were }(j)}(m)} \frac{1}{\frac{W}{\left(E_{b} / N_{0}\right)_{i j}^{(m)} R_{i j}^{(m)} v_{i j}{ }^{(m)}}+\left(1-\alpha_{(\text {moy })}\right)}
\end{aligned}
$$

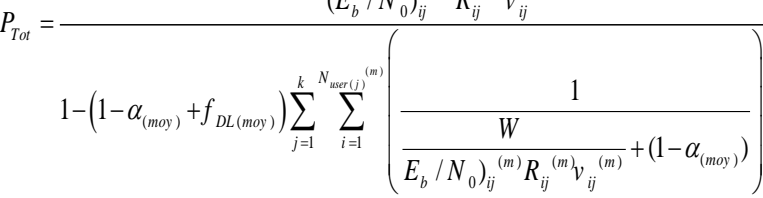

Where:

- $\alpha_{(\text {moy })}$ is the average orthogonality factor,

- $f_{D L(m o y)}$ is the average other-to-own-cell interferences ratio,

- $\quad L_{(\text {moy })}$ is the average pathloss in the cell.

In the case of an isolated cell, the other-to-own-cell interferences ratio $f_{D L}$ is equal to zero. Consequently, equation (10) can be rewritten as:

$$
\begin{aligned}
& P_{N} L_{\text {(moy })} \sum_{j=1}^{k} \sum_{i=1}^{N_{\text {uer }(j)}{ }^{(m)}} \frac{1}{\frac{W}{\left(E_{b} / N_{0}\right)_{i j}{ }^{(m)} R_{i j}{ }^{(m)} v_{i j}{ }^{(m)}}+\left(1-\alpha_{(\text {moy })}\right)}
\end{aligned}
$$

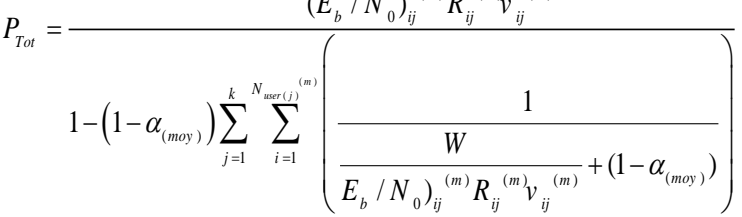

\section{WCDMA cell loading estimation}

Equation (10) can be rearranged as:

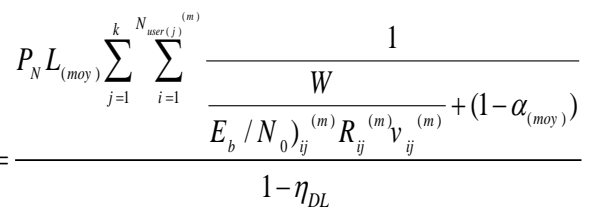

Where:

$$
\eta_{D L}=\left(1-\alpha_{(\text {mox })}+f_{D L(\text { moy })}\right) \sum_{j=1}^{k} \sum_{i=1}^{N_{\text {orof }(m)}^{(m)}}\left(\frac{1}{\frac{W}{\left.E_{b} / N_{0}\right)_{i j}^{(m)} R_{i j}^{(m)} v_{i j}^{(m)}}+\left(1-\alpha_{(\text {moy })}\right)}\right)
$$


$\eta_{D L}$ is the cell loading factor. It increases with the number of users in the cell. Generally, we take $0 \leq \eta_{D L}<1$ in order to maintain the system stability.

When $\eta_{D L}=1$, the Node B total required power tends towards infinity and the system reaches its pole capacity. Thus, in the case of a voice service only, we obtain:

$$
N_{\text {user_pôle }}{ }_{(m)}=\left(\frac{\frac{W}{\left.E_{b} / N_{0}\right)_{i j}^{(m)} R_{i j}^{(m)} v_{i j}^{(m)}}+\left(1-\alpha_{(\text {moy })}\right)}{1-\alpha_{(m o y)}+f_{D L(m o y)}}\right)
$$

Therefore the maximum number of users should satisfy the following inequality:

$$
N_{\text {user_max }}{ }^{(m)}<\left(\frac{\frac{W}{\left.E_{b} / N_{0}\right)_{i j}^{(m)} R_{i j}^{(m)} v_{i j}{ }^{(m)}}+\left(1-\alpha_{(\text {moy })}\right)}{1-\alpha_{(\text {moy })}+f_{D L(\text { moy })}}\right)
$$

In the case of two services, the cell loading factor expression is the sum of cell loading factor generated by each service $[6,7]$.Thus:

$$
\eta_{D L}=\sum_{j=1}^{k=2} \eta_{D L}
$$

Where $\eta_{D L_{j}}$ is the loading factor of a cell activate a service $j$ and $k$ is the number of services. In the case of an isolated cell, the cell loading factor can be rewritten as:

$$
\eta_{D L}=\left(1-\alpha_{(m o v)}\right) \sum_{j=1}^{k} \sum_{i=1}^{N_{m a v i(m)}^{(m)}}\left(\frac{1}{\frac{W}{\left.E_{b} / N_{0}\right)_{i j}^{(m)} R_{i j}^{(m)} v_{i j}^{(m)}}+\left(1-\alpha_{(m o v)}\right)}\right)
$$

\section{Capacity and coverage tradeoff}

From equation (12), the maximum path loss in downlink can be defined as:

$$
L_{\max }=\frac{P_{\max }}{P_{N} \sum_{j=1}^{k} \sum_{i=1}^{N_{\text {uer }(j)}^{(m)}} \frac{1}{\frac{W}{\left(E_{b} / N_{0}\right)_{i j}^{(m)} R_{i j}^{(m)} v_{i j}^{(m)}}+\left(1-\alpha_{(\text {moy })}\right)}}\left(1-\eta_{U L}\right)
$$

\section{E. Admission Control}

When the system operates at nearly the maximum capacity, admitting a new user may affect the stability of the system.

Thus, admission control AC is crucial for balancing between the quality of service requirement of the new user and for the ongoing connections, and consequently preventing the system from an outage situation due to overloading. In this paper, we present two admission control algorithms presented in the literature.

The first is based on Node B total power and the second is based on cell loading factor [9-11]. We proposed another based on both the last two parameters.

Admission control strategies based on power estimation, must take into account whether the Node B has enough power to ensure the quality of service requirements for the new requests and for connections already established.

When a new call $i$ arrives, the AC algorithm computes the minimum required transmission power for this call, and verifies the power constraint given by:

$$
\sum_{a=1}^{n} k_{i j}{ }^{(m)} P_{T o t} \leq P_{\max }
$$

Where $\mathrm{n}$ is the new number of users if accepting the new call $i$. If the constraint is satisfied, the AC algorithm accepts the new call and allocates power $p_{i j}{ }^{(m)}$ to the latter. Otherwise the call is blocked.

The second admission control algorithm is based on the maximum cell loading factor threshold. This parameter determines the admission of new calls in the network. When the cell loading factor of the Node B is below this threshold, a new call is accepted in the network. Above this threshold a new call is blocked at admission $[11,12]$.

The following equation shows the constraint that must be verified:

$$
\eta_{D L}+\Delta \eta \leq \eta_{D L_{-} \max }
$$

Where $\eta_{D L}$ is the current cell loading factor, $\Delta \eta$ the is the increase cell loading factor due to the new call and $\eta_{D L_{-} \max }$ is the maximum cell loading factor threshold setting by the operator at the dimensioning phase.

We propose an admission control algorithm which is based at the same time on the maximum cell loading factor and on the total available power at the Node B.

The following diagram illustrates this algorithm: 


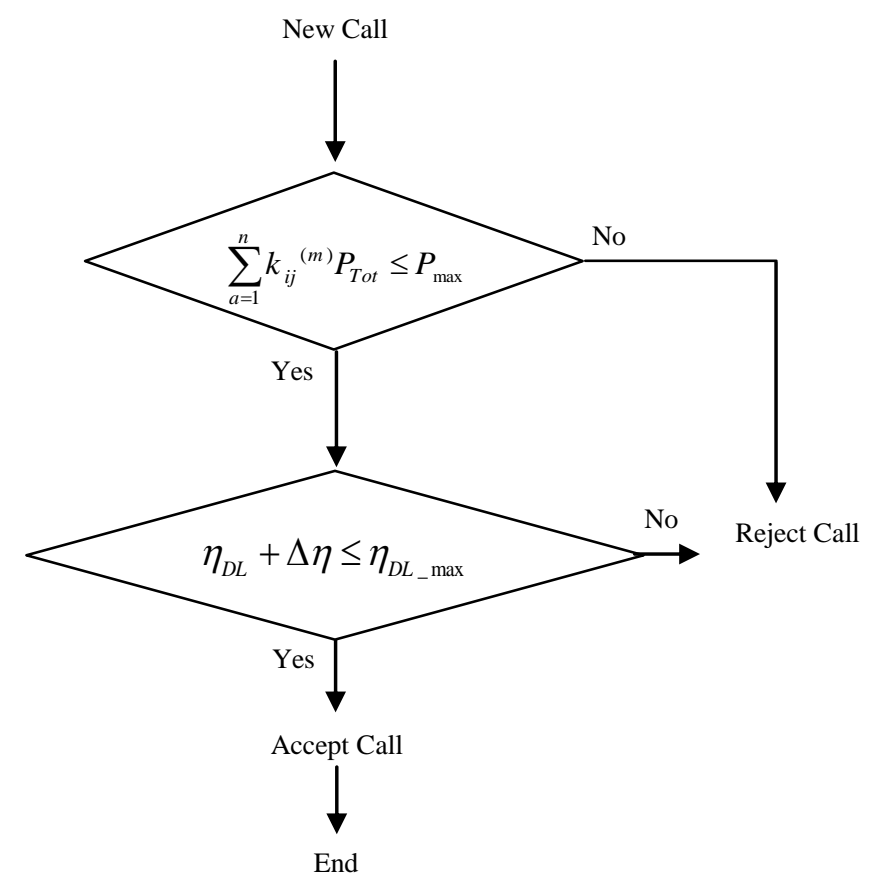

Fig.1. Admission control algorithm.

\section{SIMULATION PARAMETERS}

The simulation parameters correspond to a macro-cellular network using omnidirectional antennas and Okumura-Hata propagation model which is written as:

$$
L=137+35,2 \log 10(d), d \text { is in }(\mathrm{km})
$$

Where $\mathrm{d}$ is the distance separating the mobile and the serving Node B.

The average pathloss value was $133 \mathrm{~dB}$ and the maximal Node B power $P_{\max }$ was $20 \mathrm{Watt}(43 \mathrm{dBm})$. The value of $W$ is $3,84 \mathrm{Mcp}$, the average orthogonality factor is 0,6 and the thermal noise is $-100 \mathrm{dBm}$.

Figures 2 and 3 show the variation of the Node B total required power as a function of the number of users in a cell activating only voice service $(R=12,2 \mathrm{kbit} / \mathrm{s})$ and in a cell activating voice/video $(R=66,5 \mathrm{kbit} / \mathrm{s})$, respectively, for two different scenarios.

The target ratio $E_{b} / N_{0}$ for the voice service and video service are 5,5 $\mathrm{dB}$ and $6,5 \mathrm{~dB}$ respectively. The activity factor for voice and video are 0,67 and 1 respectively.

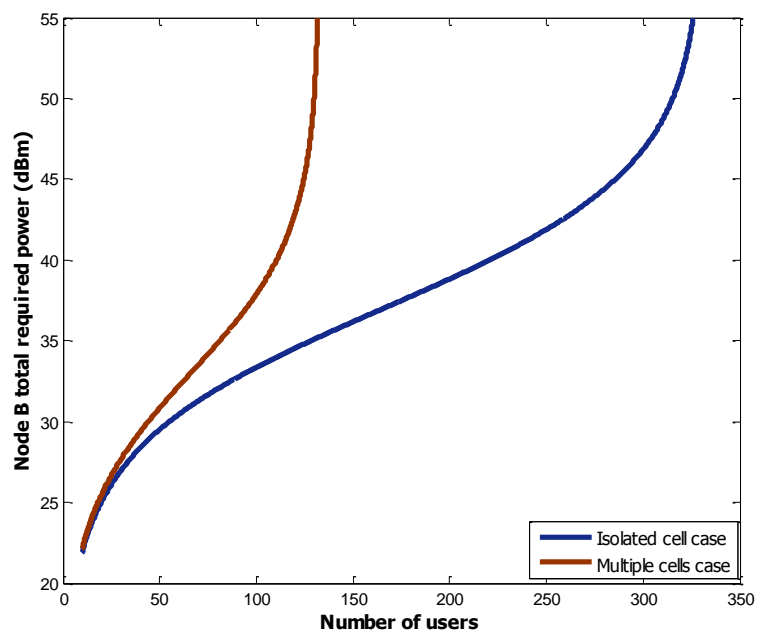

Fig.2. Node B total required power for voice service in the case of two scenarios.

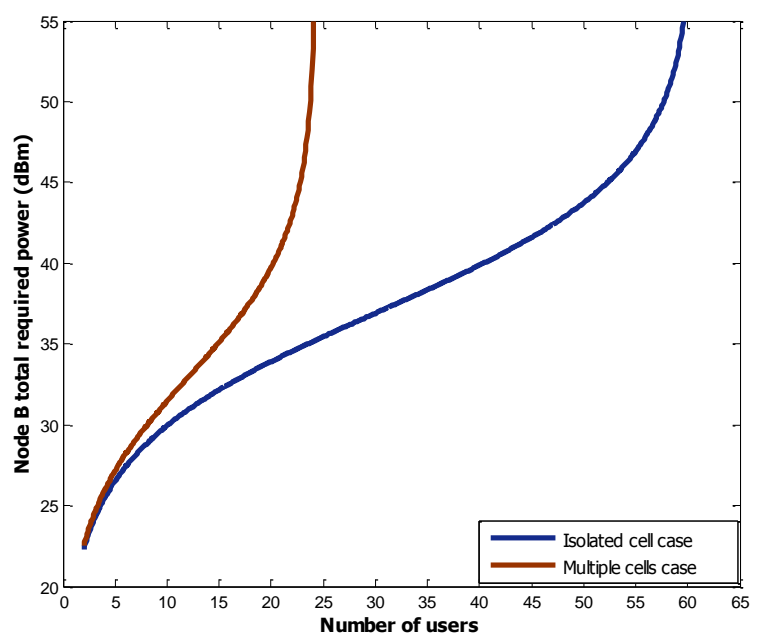

Fig.3. Node B total required power for voice/video services in the case of two scenarios.

From these figures, we note that the maximum cell capacity supported in an isolated cell case is more important than that supported in a multiple cells case. This is mainly due to the high-level of interference caused by the neighboring cells load in the last case, which lead to higher power consumption to ensure the target $E_{b} / N_{0}$. Therefore, the cell becomes loaded for a very small number of users. 
In addition, the Node B power consumed by mobile stations in the case of a cell activating voice/video is much greater than that consumed in the case of a cell activating voice.

Figures 4 and 5 show the variation of the Node B total required power as a function of the number of users in a cell activating only voice service and in a cell activating voice/video respectively, for different values of $f_{D L}$.

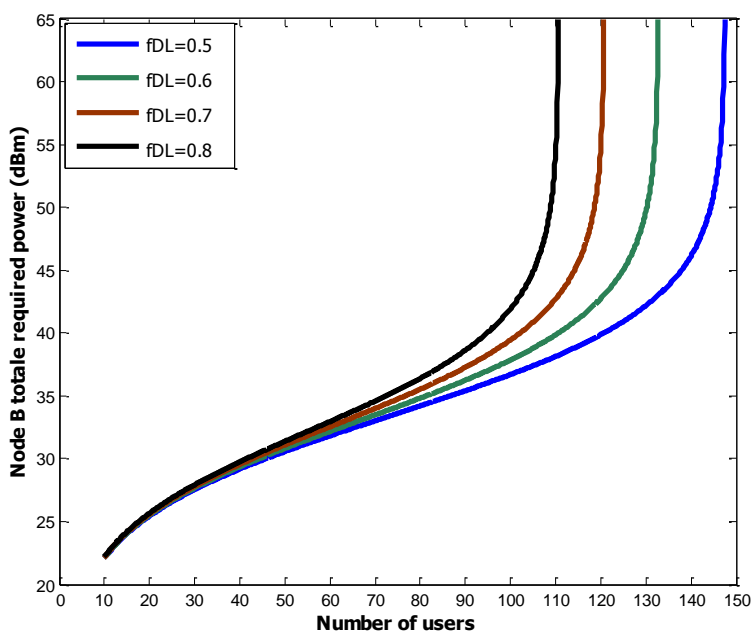

Fig.4. Node B total required power for voice service in the case of different values of $f_{D L}$.

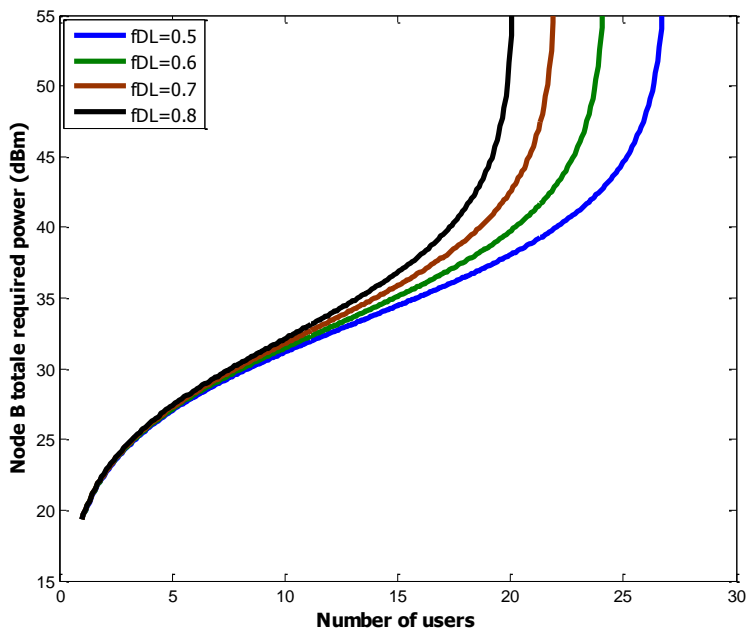

Fig.5. Node B total required power for voice/video services in the case of different values of $f_{D L}$.

According to figure 4, we notice that the Node B total required power increases with the number of active users in the cell, for a given value of $f_{D L}$.

By setting up the number of users and varying factor $f_{D L}$, we find that the value of the Node B total required power increases with the interference factor fDL. That is due to the increase of interference level in the cell, affecting the useful signal.
From figure 5, we note first that, the need of Node B total required power according to the number of active users in the cell increases in an important manner in comparison with the one in a cell activating only one service as shown in figure 4. Therefore, the Node B becomes saturated for a very small number of users since the total required power exceeds the maximum transmission power $P_{\max }$ available at the Node B. This means that the Node B cannot serve all the mobile stations with the required quality of service. On the other hand, the maximum capacity of a network with two services is much lower than the one of a single service network. This capacity decreases with increasing $f_{D L}$ factor. For $f_{D L}=0.5$, the maximum number of users supported by the Node B is about 24 users, while for $f_{D L}=0.8$ the maximum number supported is about 18 users.

The following figure shows the variation of the cell loading factor as a function of the number of users activating only voice service, for two types of scenarios.

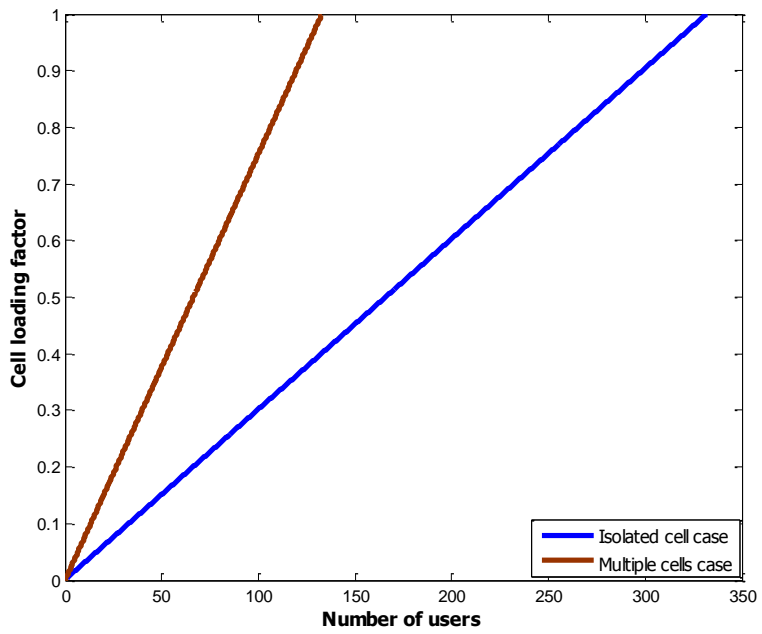

Fig.6. Cell loading factor as a function of the number of users activating voice service for two different scenarios.

According to this figure, we note that in the case of an isolated cell, the pole capacity is reached for approximately 331 users, whereas in the case of multiple cells, the pole capacity is reached for only 132 users approximately. This decrease in capacity is explained by the other-cell interferences that negatively affect the quality of service of active users in the cell of study. Therefore, users needing more power to meet their $E_{b} / N_{0}$ target value. Consequently, the maximum number of users that can support the cell decreases.

During the dimensioning phase, an operator may set, according to his needs, the value of the maximum cell loading factor $\eta_{D L_{-} \max }$. This value must be always strictly less than the pole cell loading factor.

In the case of two services: voice and video, the variation of cell loading factor for two different scenarios is presented in the following figure: 


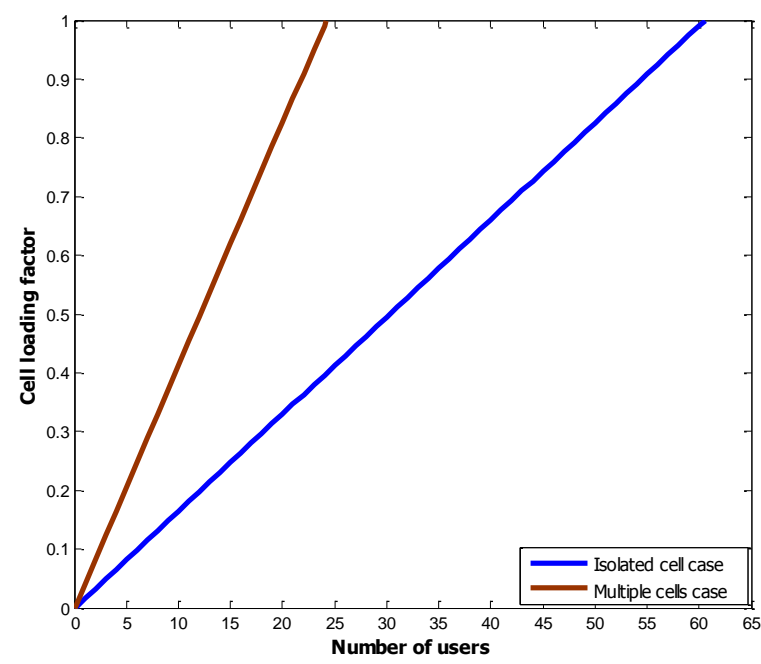

Fig.7. Cell loading factor as a function of the number of users activating voice/video services for two different scenarios.

From this figure we note that in the case of an isolated cell, the pole capacity is reached for approximately 60 users, while, in the case of multiple cells, the pole capacity is reached for only 24 users approximately. In addition, and according to figure 6 , the pole capacity in both scenarios, is more important than in the case of two services: voice and video. This is due to the increase in power to devote to mobile stations in the latter case. Therefore, the maximum number of users that can support the cell decreases.

The following figure illustrates the variation of the transmitted power devoted to a given mobile station activating video service, according to the distance that separates it from its Node B. The coverage radius is taken equal to $2 \mathrm{~km}$.

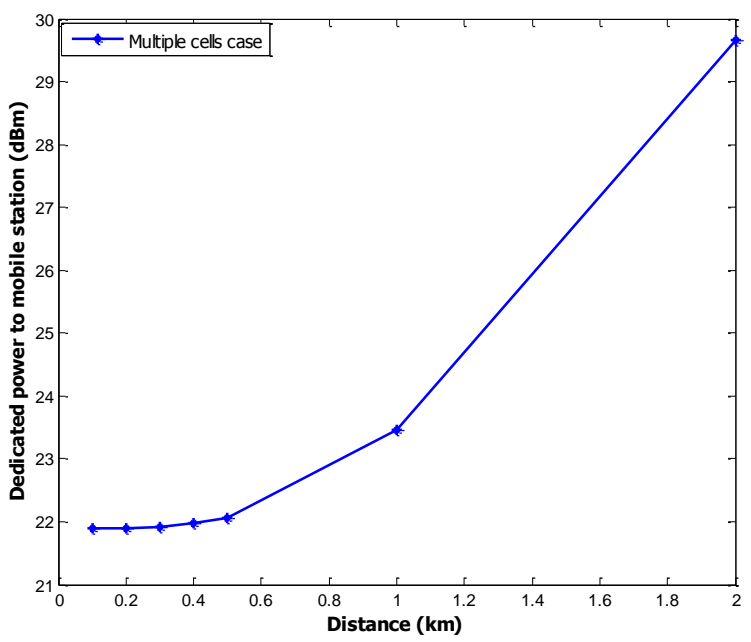

Fig.8. Dedicated power to mobile station according to distance in the case of multiple cells case.
From this figure and for distances less than $0.6 \mathrm{~km}$, one can observe that the transmitted power dedicated to the mobile station as a function of the distance which separates it from its serving Node B, is almost constant. This is due mainly to the low pahloss existing for short distances, which means that the second term of the equation (3) is negligible compared to the first which does not depend on the pathloss.

For high distances, more the mobile station approaches the periphery of the cell; we observe that the transmitted power devoted to it increases significantly. This is due to the large distance between the mobile station and its serving Node B, which means that the second term of the equation (3) becomes

non negligible in long distances

Another cause of this increase in power is the high level of other-cell interferences existing in large distances which affects the quality of service of the existing mobile station on the cell periphery.

Figure 9 shows the blocking probability according to the number of new requests in the case of two scenarios by using the AC based on the Node B total power.

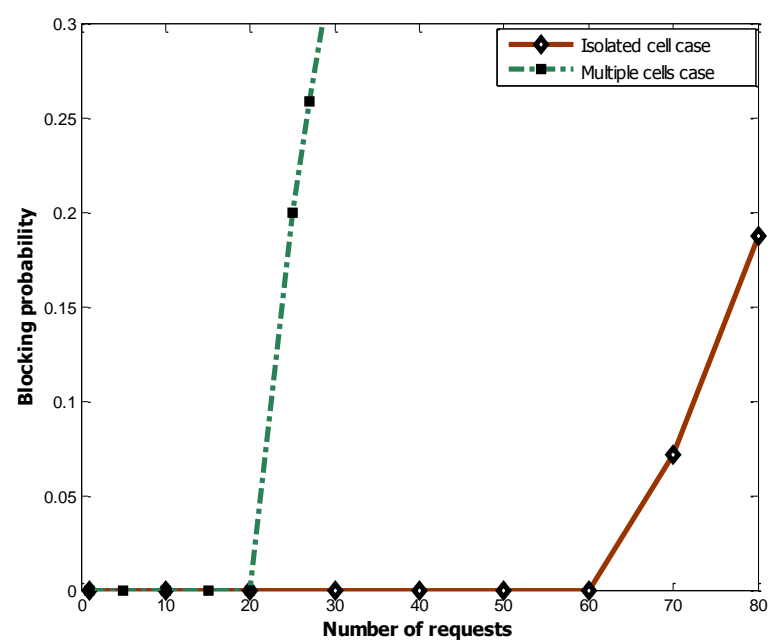

Fig.9. Blocking probability as a function of voice requests in the case of two scenarios.

From figure 9 we notice that the blocking probability in the case of an isolated cell, where there is an absence of other-cell interferences, is much smaller than that presented in the case of a network with multiple cells.

Effectively, in the case of a single cell, the number of requests simultaneously admitted is 60 , while in the case of multiple cells; the cell can accept only 20 concurrent requests.

Figure 10 shows the blocking probability according to the number of new requests in the case of two scenarios by using the $\mathrm{AC}$ based on the cell loading factor. 


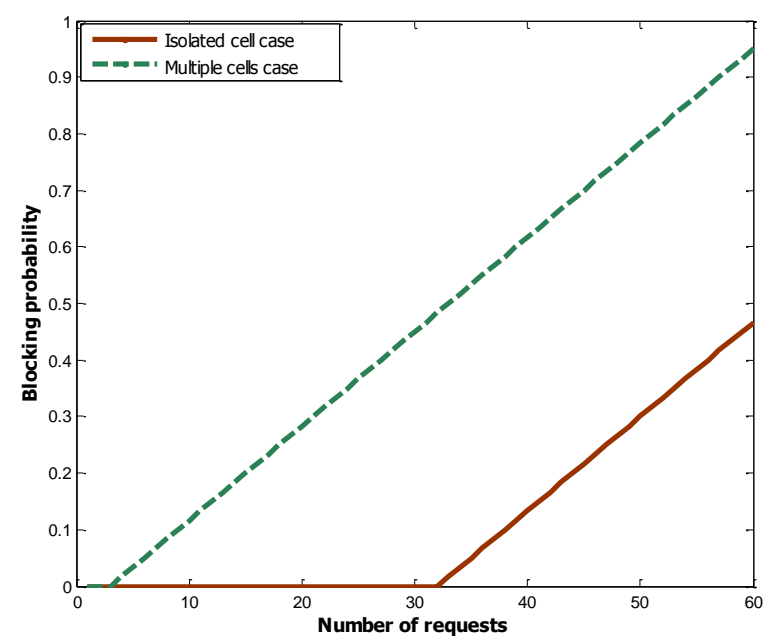

Fig.10. Blocking probability as a function of voice requests in the case of two scenarios.

From this figure, we note that, the blocking probability seen in the case of a single cell is much lower than in the case of multiple cells. This is mainly due to the absence of other-cell interferences in the first case, which makes the cell able to accept a large number of requests. According to this figure, the number of simultaneously accepted requests in the case of an isolated cell is approximately 32 , while in the case of multiple cells the number of requests is approximately equal to 4 .

Figure 11 shows the variation of the blocking probability according to the number of new requests in the case of the proposed algorithm:

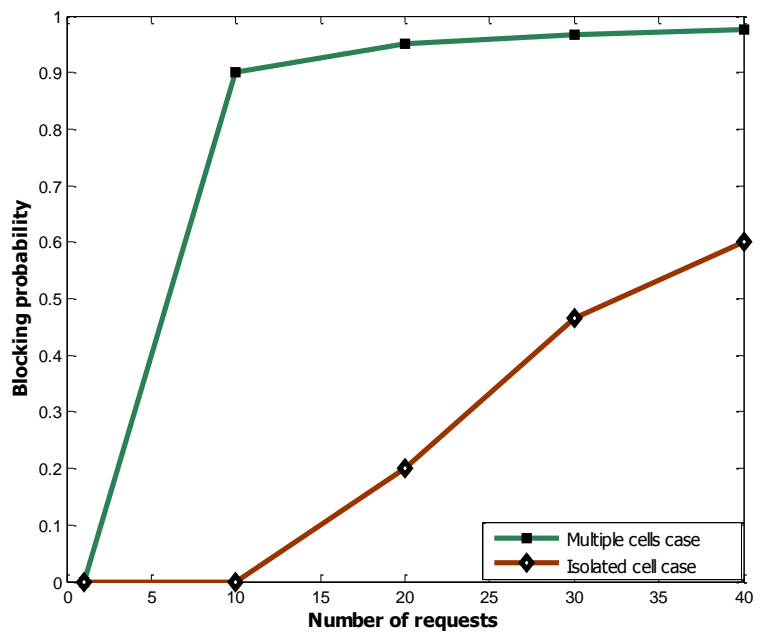

Fig.11. Blocking probability as a function of voice requests in the case of two scenarios.

From this figure we see that the blocking probability found with the proposed algorithm is greater than the one found by the application of power $\mathrm{AC}$ and cell loading factor $\mathrm{AC}$ for the two used scenarios. These results are more rigorous and more realistic.

\section{CONCLUSION}

We have discussed in this paper the effect of other-to-owncell interferences ratio $f_{D L}$ on Node B total required power and maximum cell capacity, in downlink direction.

We found that more the other-cell interferences level is high, the more there is an increase in the first parameter and a decrease in the last one. In addition, in order to overcome the overloading situation, we present two admission control algorithms, the first is based on the Node B total power and the second is based on the cell loading factor. We have proposed a third which is based on the load and power at the same time. The application of this algorithm gives more realistic and rigorous results.

The study of the three AC algorithms is made for two different scenarios: An isolated cell and multiple cells cases. The results show that the effect of neighboring cells increase the blocking probability of new requests.

\section{References}

[1] Chie Dou, Yu-Hua Chang, Class-based downlink capacity estimation of a WCDMA network in a multiservice context, Computer Communications 28 (2005) 1443-1455, 13 January 2005.

[2] Kari Sipilä et al, Estimation of Capacity and Required Transmission Power of WCDMA Downlink Based on a Downlink Pole Equation, Vehicular Technology Conference 2000.

[3] Fadoua Thami Alami, Noura AKNIN, Ahmed El Moussaoui, Capacity estimation of multi-service network, Dimensioning and planification network, International Journal on Computer Science and Engineering, Vol. 3 Issue 3, 2011.

[4] Thrasivoulos (Sakis) Griparis, Tristan Lee, The capacity of WCDMA network: A case study, Bechtel Telecommunications Technical Journal, Vol. 3, No. 1, august 2005.

[5] Nicolas Enderlé, Xavier Lagrange, Analyse de la capacité descendante d'un système WCDMA, Actes du congrès DNAC, novembre 2001.

[6] Kimmo Hiltunen, Riccardo De Bernardi, WCDMA Downlink Capacity Estimation, Vehicular Technology Conference Proceedings. VTC 2000Spring Tokyo. 2000 IEEE 51st, Volume 2, Issue, 2000 Page(s): 992 996 vol. 2. 2000.

[7] Jordi Pérez-Romero, Oriol Sallent, Ramon Agust1', Radio Resource Management Strategies In UMTS, John Wiley \& Sons, Ltd, The Atrium, Southern Gate, Chichester, West Sussex PO19 8SQ, England, 2005.

[8] Soumaya Hamouda, Philippe Godlewski, Sami Tabbane, Downlink Capacity Estimation for UMTS Network: Impact Of Users'Position, Service Bit Rates And Cell Radius, Print ISBN: 978-9972-61-100-1, Issue Date: 11-14 Dec. 2005.

[9] J. Pérez-Romero, O. Sallent, D. Ruiz, R. Agustí, An Admission Control Algorithm to Manage High Bit Rate Static Users in W-CDMA, Dept. of Signal Theory and Communications, Universitat Politécnica de Catalunya.

[10] Gaurav Bansal, A. K. Chaturvedi†, and Vijay K. Bhargava, Distributed Admission Control for Power-Constrained Cellular Wireless Systems, Department of Electrical and Computer Engineering University of British Columbia, Vancouver, Canada, Print ISBN: 1-4244-1020-7, EISBN: 1-4244-1021-5, Issue Date: 22-26 April 2007.

[11] Zdeněk RŮŽIČKA, Stanislav HANUS, Admission Control And Load Control In UMTS Network, Institute of Radio Electronics, Brno University of Technology Purkyňova 118, 61200 Brno, Czech Republic, contract no. 102/03/H109 and no. 102/04/2080.

[12] GUSTAVO AZZOLIN DE CARVALHO PIRES, Multi-Cell Admission Control for WCDMA Networks, Master of Science Thesis, Stockholm, Sweden 2006. 